\title{
FEASIBILITY OF POWERING MANZANILLA VIA A WIND FARM
}

\section{Mickhal Polisher ${ }^{1}$, Edward Cumberbatch ${ }^{2 *}$, Aneil Ramkhalawan ${ }^{3}$, Jorrel Bisnath $^{4}$, Aatma Maharajh ${ }^{5}$}

1,2,3,4,5 Design \& Manufacturing Systems, The University of Trinidad and Tobago, Trinidad

${ }^{1}$ Email: m.polisher@outlook.com

${ }^{2}$ Email: edward.cumberbatch@utt.edu.tt*(Corresponding author)

${ }^{3}$ Email: aneil.ramkhalawan@utt.edu.tt

${ }^{4}$ Email jorrel.bisnath@utt.edu.tt

${ }^{5}$ Email: aatma.maharajh@utt.edu.tt

\begin{abstract}
Remote communities on the outskirts of Trinidad and Tobago have the perennial challenge of a reliable supply of electricity. Frequent outages can have a negative effect on the quality of life for persons in such areas. Manzanilla is one such community. It however lies on the east coast of Trinidad. The east coast is commonly thought to have a significant wind resource compared with other areas of Trinidad. This study looked at the feasibility of providing wind energy to a community in the Manzanilla area. Average power consumption was determined by a survey for a total of almost 300 households, businesses and combined establishments in the area. The wind resource was examined to determine if it could meet the electricity demand which has been growing steadily from 2001 to the present. The wind resource was found to be adequate when compared with similar areas considering the generation of wind energy.
\end{abstract}

Keywords: Electricity demand, Remote communities, Wind resource.

https://doi.org/10.47412/AIEL3127

\section{Introduction}

\section{Rationale}

There has been an increase in countries moving towards cleaner and renewable energy sources. Gielen et al [1] project an optimistic increase in the renewable energy share of energy markets from 15\% in 2015 to $63 \%$ by 2050. Many countries have adopted quite aggressive goals to facilitate this increase. It signals a global trend in the energy sector to move away from the fuel that Trinidad and Tobago both uses and produces. There is an opportunity to expand our energy sources as well as change our economy before the global trends harshly turn against our current economy.

Trinidad and Tobago, according to the Ministry of Energy and Energy Industries [2], generates the majority of its electricity via Powergen, Trinity Power and Trinidad Generation Unlimited (TGU) from burning natural gas. While obtaining power via this method is effective, burning fossil fuels is one of the world's leading producers of greenhouse gases and while burning natural gas is much cleaner than burning coal, it still produces gases that can lead to global warming. In order to reduce Trinidad and Tobago's carbon footprint an alternate clean energy source is required.

This project focuses on the coastal village of Manzanilla, specifically the North Manzanilla road and the Eastern main road stretch located between the Manzanilla Gas Station and the Manzanilla Beach. The area of Manzanilla, specifically near the coast, tends to be relatively windy. These conditions can prove to be 
beneficial for producing electricity using the wind found near the coastline or just offshore. Manzanilla tends to have a relatively large number of power outages. Providing an alternate source of power to these communities can act to insulate the residents from having to experience the outages.

This project aims to solve the problem of the electricity irregularity faced by the residents of Manzanilla as well as to provide an alternate source of clean energy for the community.

\section{Objectives}

The objectives of this project are as follows:

- To determine the average power consumption of the area of Manzanilla under focus

- To determine if the wind power resource in the area can be used to meet the demand of Manzanilla

- To propose a wind farm style to maximize the power obtained from the resource available

\section{Scope}

The scope of this project was to assess the feasibility of installing a windfarm within the Manzanilla area, specifically to deliver power to the communities in the area between the Manzanilla gas station and the coastline following along the Eastern main road as well as the North Manzanilla road. In doing this, the scope included acquiring the power consumption of the area under study and accessing the wind patterns of the area for viability of electricity generation.

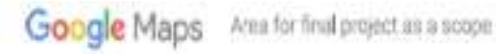

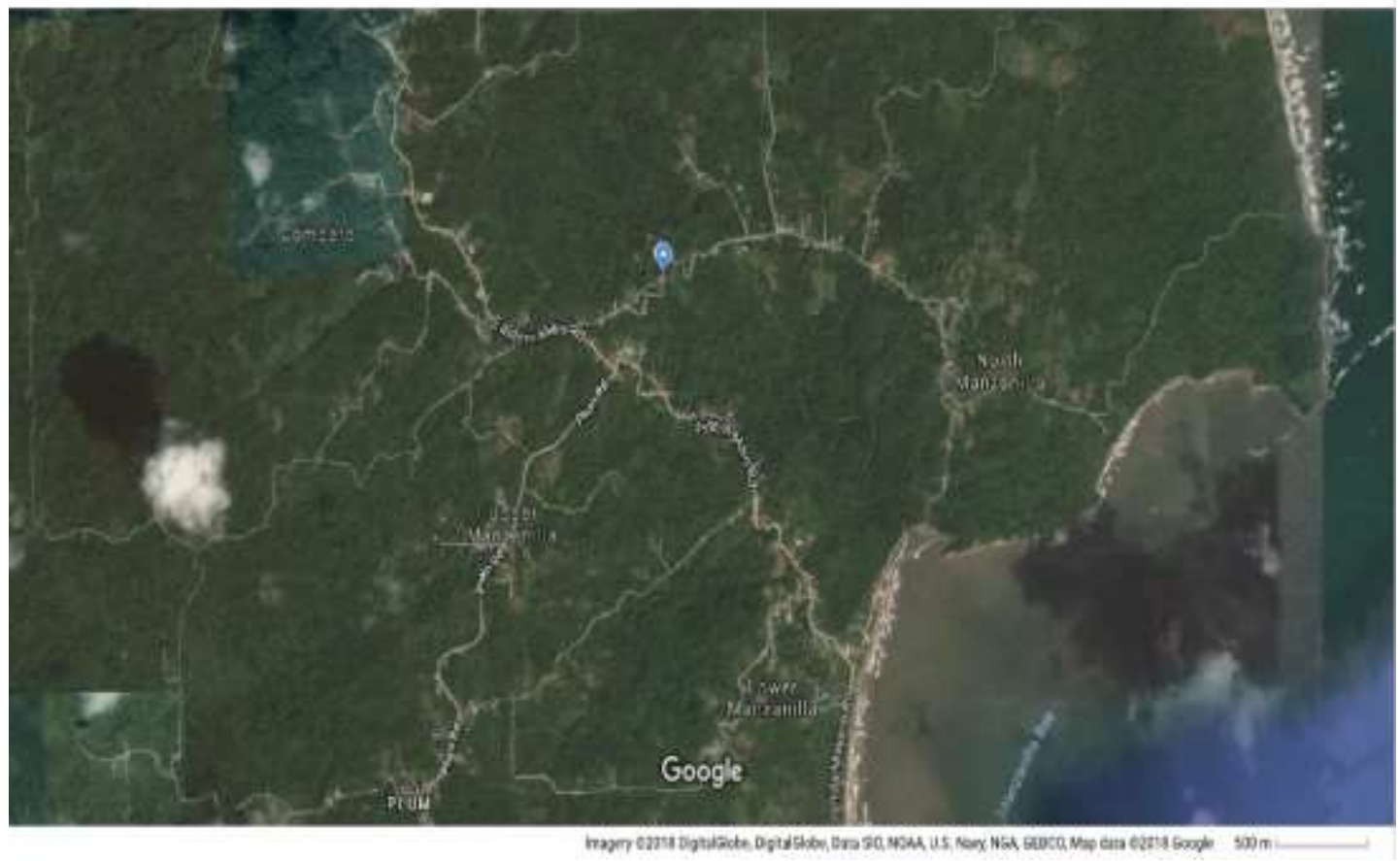

Figure 33: Image depicting the Manzanilla section currently under study [3]

\section{Literature Review}

The approximate range of usable wind speeds for electricity generation are between $4.5 \mathrm{~ms}^{-1}(10 \mathrm{mph})$, cut-in wind speed, through $12 \mathrm{~ms}^{-1}$ (27 mph), rated wind speed, up to $22 \mathrm{~ms}^{-1}$ (50 mph) cut-out speed [4]. Corresponding values can be lower for small systems [5]. 
Research into installing wind farms in the country of Trinidad and Tobago is limited. Of the few that do exist, most focus primarily on the environmental impact of installing wind farms in specific areas. A study conducted by Ramnarine-Ramsawak \& Ramroop [6] shows the effects of installing an offshore wind farm concluding that installing such a farm would be environmentally infeasible but also shows that there is potential for wind farms. However, as the study focuses on environmental effects, their data does not look in depth at the sustainability of said wind farm.

Trinidad and Tobago currently has some companies involved in the renewable energy sector. However, these companies do not use wind as their primary focus and in those that do investigate some measure of wind energy, as with those listed on the Source for Renewable Energy website, "Renewable Energy Businesses in Trinidad \& Tobago" [7], their application for wind energy is quite small. These companies try to appeal to the small-scale market for personal and private use. The intention of this project was to be able to deliver electricity on a larger scale for an entire neighbourhood in rural Trinidad.

In Trinidad and Tobago today, studies on clean, low emission energy focus on non-wind sources and those that use wind as a backdrop do not exclusively focus on the possibility of power generation in our country.

In the report, Framework for the development of a renewable energy policy for Trinidad and Tobago [8], a trend for the rising demand for energy within Trinidad and Tobago was presented. This project, if shown to be feasible, can provide a path for an alternate supplemental source of electricity, not only for the target region but also for similar regions across the country.

\section{Data Gathering}

Background information on the minimum requirements of wind farms to generate electricity was obtained. The required output of the wind farm needed to be estimated. To accomplish this, the size of the target area was found. An interview of each resident within the outlined area helped to establish their power needs from the electrical network established by the Trinidad and Tobago Electricity Commission. Based upon the number of existing connected customers, an estimate of their potential power drain per month was obtained followed by more accurate values obtained from the T\&TEC. Additionally, information on the wind patterns in the area, either over the land, near the coastline or offshore, was obtained for viability of the wind farm. Wind turbine design was researched in order to optimize the electricity gained from the wind resources in the area. Finally, a cost estimate for the construction of the wind farm was determined.

\section{Community Size}

The size of the community was found using a door to door tally method in conjunction with an interview of a random sample of the people in the area.

Table 42: Table showing total population along both the Eastern main road in Manzanilla and North

Manzanilla Road using the coastline and the Manzanilla gas station as the limits of the area

\begin{tabular}{|c|c|c|c|}
\hline Type & $\begin{array}{l}\text { Eastern Main Road, } \\
\text { Manzanilla }\end{array}$ & $\begin{array}{l}\text { North Manzanilla } \\
\text { Road, Manzanilla }\end{array}$ & Total \\
\hline Residences & 156 & 79 & 235 \\
\hline Businesses & 29 & 8 & 37 \\
\hline Combinations & 16 & 9 & 25 \\
\hline Totals & 201 & 96 & 297 \\
\hline
\end{tabular}


The community spread shown in Table 1 has a specific power requirement. Originally, an estimate of the power consumption was obtained using data gathered from several participants of an interview conducted in the area with a random sample of 50 participants. Using the information gathered from the participants an average power consumption was estimated based upon their bi-monthly bills.

\section{Energy Consumption}

The mean cost of each bill was TT $\$ 600.00$ bi-monthly. Using the Appliance Usage document [9], it was calculated that the mean electrical energy fell approximately between 900 and $1000 \mathrm{kWh}$ per household per month. The total energy consumption for the area was determined to be between 267,300 and $297,000 \mathrm{kWh}$ used per month. These numbers were based on mean values of the sample of the data collected and more accurate values for this variable were required for continued study.

T\&TEC gave the daily power consumption of the area to be approximately 1 Mega Volt Amp (MVA).

\section{Wind Speed}

Wind data used in this study showed an interesting wind speed array. The average wind speed on the eastern seaboard was shown to be between 10 and $14 \mathrm{mph}$. The measuring station used was located in Mayaro, which is south of the area of study. The data was obtained from the website Windfinder [10]. Values were determined at $10 \mathrm{~m}$ above the ground. Figures for a week of wind speed observations are shown in Table 2 below.

In addition to the above wind data there was also a yearly average wind speed chart obtained from the website Weather Spark using a different measuring location. The location used for this data was the town of Rio Claro located further south of the area of study but still close to the eastern coast which gave a reasonable representation of the wind conditions in the area.

Table 43: Table showing a capture of local wind speeds over the first seven days of April 2019

\begin{tabular}{|l|l|}
\hline Date & Wind Speed \\
\hline Monday April $1^{\text {st }}$ & $11 \mathrm{mph}$ \\
\hline Tuesday April 2 $^{\text {nd }}$ & $13 \mathrm{mph}$ \\
\hline${\text { Wednesday April } 3^{\text {rd }}}^{\text {Thursday April 4 }}$ & $12 \mathrm{mph}$ \\
\hline Friday April $5^{\text {th }}$ & $10 \mathrm{mph}$ \\
\hline Saturday April $6^{\text {th }}$ & $12 \mathrm{mph}$ \\
\hline Sunday April $7^{\text {th }}$ & $14 \mathrm{mph}$ \\
\hline
\end{tabular}




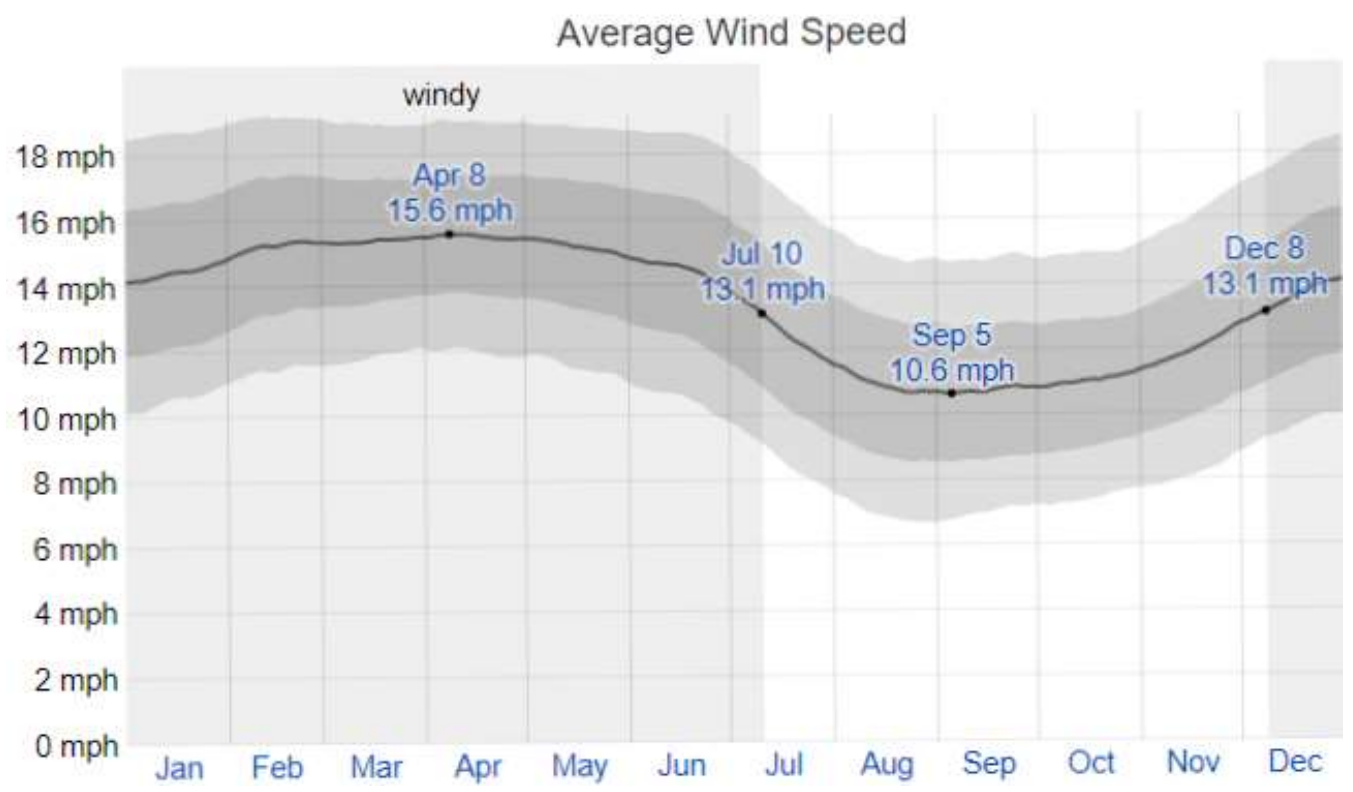

Figure 2: Showing average hourly historical wind speed in Rio Claro over a year [11]

WeatherSpark's wind data comes from NASA's MERRA-2 Modern Era Retrospective Analysis. An hourly history is reconstructed on a $50 \mathrm{~km}$ grid based on data collected from 1980-2016. The wind speeds here were also determined for a height of $10 \mathrm{~m}$ above the ground. It is expected that the wind speeds would be higher at $80 \mathrm{~m}$, the typical height of large wind turbines. Figure 2 shows a peak mean wind speed of $15.6 \mathrm{mph}$ earlier in the year and a low of $10.6 \mathrm{mph}$ later in the year. These two speeds fall within the range of values observed in Mayaro. While both monitoring points are not located within the point of interest, due to the size of the island of Trinidad and the fact that the both locations are on the eastern half of the island, the assumption that the wind conditions in the area match the data with low variance can be made.

\section{Costs}

Wind turbines vary in cost based upon application as well as based upon its power output. In the private residential circle, according to windustry.org [12], the turbines which can produce under $100 \mathrm{~kW}$ can cost anywhere between US\$3,000 and US\$ 8,000 for each kilowatt of production capacity. Installation costs for a $10 \mathrm{~kW}$ turbine, which could power a large home, are between US\$ 50,000 and US\$ 80,000. As an example, the $10 \mathrm{~kW}$ GridTek set up for residential applications can cost anywhere between US $\$ 40,000$ - US $\$ 60,000$.

For the industrial sector costs for turbines that can generate on the scale of a utility can cost anywhere within the range of 1.3 to 2.2 million USD dependent on the wattage rating of the turbine. When considering costs of the wind farms the turbines are merely one aspect of the construction. The support structure as well as the delivery systems are required for proper operations and electricity generation. These resources all vary in cost with their construction style and the nature of wind farms they are attached to. In addition to these costs there are maintenance costs to consider. Typically, turbine manufacturers offer maintenance programs for their individual turbines. These can vary in cost across manufacturers as well as turbine capacity. Below is a table showing some of the costs associated with maintenance of the turbines themselves.

Table 44: Table showing Annual Maintenance Costs for Specific types of wind turbines [13] 


\begin{tabular}{|c|c|c|}
\hline Power Output & Typical Turbine Type & $\begin{array}{c}\text { Annual Operations \& } \\
\text { Maintenance cost per kW }\end{array}$ \\
\hline $55 \mathrm{~kW}(10 \mathrm{~m} / \mathrm{s})$ & Endurance E-3120 & US\$ 85 \\
\hline $500 \mathrm{~kW}(10 \mathrm{~m} / \mathrm{s})$ & $\begin{array}{c}\text { EWT DW52/54 } \\
\text { or }\end{array}$ & US\$ 68 \\
\hline $800 \mathrm{~kW}(12 \mathrm{~m} / \mathrm{s})$ & Enercon E53/48/44 & US\$ 62 \\
\hline $1.5 \mathrm{MW}(12 \mathrm{~m} / \mathrm{s})$ & Enercon E53/48/44 & US\$ 61 \\
\hline $2-3 \mathrm{MW}(12 \mathrm{~m} / \mathrm{s})$ & GE $1.5 \mathrm{~s} 1$ & US $\$ 53$ \\
\hline
\end{tabular}

Table 3 above shows that although the higher power rated turbines are more expensive to maintain, the cost per $\mathrm{kW}$ is significantly reduced.

\section{Data Analysis/Final Design and Testing}

\section{Wind Speed}

From the wind data from Windfinder [10], a mean value for the first week of April's measured wind speed can be found:

$$
\begin{aligned}
& \text { Mean }=\sum \text { Daily Wind Speed Measurement } / \# \text { of days measured } \\
& \text { Mean }=(11+13+12+10+12+14+13) / 7 \\
& \text { Mean }=12.14 \mathrm{mph}(5.43 \mathrm{~m} / \mathrm{s})
\end{aligned}
$$

This mean value is consistent with the two other random day measurements, the high of which is $12 \mathrm{mph}$ and the lower is $10 \mathrm{mph}$. The mean is also consistent with the historical data determined for the area of Rio Claro which shows a mean of $15.6 \mathrm{mph}$ within the month of April. While this is higher than the mean value at Mayaro, it can be seen to be within the range of wind speed expected from the eastern coast. The measuring station may be in a different location geographically but the wind across the east coast seems to be consistently above $10 \mathrm{mph}$ at the locations considered. Armed with this knowledge, it can be assumed that the entire east coast should have similar wind conditions allowing the area of study to fall within the measured range of values.

\section{Area Selection}

For selecting the wind farm placement area there are some criteria to consider. The environmental impact of construction is the major consideration. In reference to Fig. 1, the area under study is covered mostly by forest. In order to construct any type of wind installation there would need to be removal of the greenery present. In addition to this, there can be concerns for the disruption of the wind flow while on land by trees or mountains. Table 4 and Table 5 list some of the advantages and disadvantages for developing wind farms on land and offshore.

\section{Land farms}

Table 45: Table listing the advantages and disadvantages of Land based wind farms

\begin{tabular}{|l|l|}
\hline Advantages & Disadvantages \\
\hline Lower operating costs & Can be noisy and disturb local residents \\
\hline \multirow{2}{*}{ More space efficient than Solar power } & Requires land space to be constructed \\
\cline { 2 - 2 } & Can disrupt behavioral patterns of animal life \\
\hline
\end{tabular}


Wind speeds can be intermittent and blocked by natural land formations

\section{Offshore}

Table 46: Table showing some of the advantages and disadvantages of offshore wind farms

\begin{tabular}{|l|l|}
\hline Advantages & Disadvantages \\
\hline $\begin{array}{l}\text { Offshore wind speeds tend to be higher than those } \\
\text { on land }\end{array}$ & $\begin{array}{l}\text { Wind farms tend to be more expensive and difficult } \\
\text { to both construct as well as to maintain }\end{array}$ \\
\hline Wind speeds tend to be more constant offshore & $\begin{array}{l}\text { When built within view of the coastline they can be } \\
\text { seen as unsightly and can possibly lead to a } \\
\text { decrease in tourism in the areas }\end{array}$ \\
\hline $\begin{array}{l}\text { Can aid more coastal areas meet energy needs via } \\
\text { wind power }\end{array}$ & $\begin{array}{l}\text { They can be an obstruction to marine life with } \\
\text { adverse effects to both human and otherwise }\end{array}$ \\
\hline
\end{tabular}

In general, offshore wind farms have the same side benefits of land wind farms such as:

1. The provision of a local energy production.

2. Low or no greenhouse gas emissions.

3. No water is required for their operations so they are less likely to pollute water sources.

4. Creates additional jobs in the area they are deployed.

The decision to use either of the wind farms will depend on the nature of the environment in which they are deployed. Figure 1 shows that there is a large mass of trees surrounding the population. Within these trees are many of the indigenous species to Trinidad and Tobago. One of these known to live in these forests is the Red Howler Monkey. These monkeys are currently a protected species under the Conservation of Wildlife Act, and an application has been made to allow them to become classified as an Environmentally Sensitive Species. Wind Energy activities can be a potential factor in tampering with the monkey's normal life cycle due to the need to remove trees in order to place turbines, transmission lines and a substation as well as the noise levels of the turbines themselves. Taking into consideration that these are only one of the many species living in this forested area, as well as the above stated disadvantages of land-based wind farms, it seems to be best to choose to install an offshore wind farm to service the Manzanilla area.

While going offshore may seem like a beneficial idea, there are still some variables to consider. There are quite a few varying types of migratory birds that fly through the area of study constantly. If a new high mechanical structure were to be installed, the potential for disruption of their migration patterns or even injury to these birds is high. Wind turbines, especially Horizontal Axis Wind Turbines (HAWTs), are placed at a height of about 80 meters in order to maximize the benefits of the unobstructed wind patterns. At these heights the spinning turbines have a chance to injure flying birds. In addition to this, particularly on the east coast, the flight paths of transport aircraft for offshore installations would become affected and would require diversion.

\section{Turbine Numbers required}

Based upon the wind speeds and the power requirements of the area in question a minimum number of wind turbines can be calculated. To begin with the total power consumption of the area per day as provided by the TTEC is known to be 1 MVA. This value provided is the apparent power consumed over a 12-hour period (6 am to $6 \mathrm{pm}$ ). Converting this apparent power value to real power requires the Power Factor of the electrical grid, quoted as 0.8 . When all these are known the conversion to real power can be done using the following equation:

Real Power $=$ Apparent Power $\times$ Power Factor 
Using the Power factor of 0.8 gives:

Real Power $=1$ MVA $\times 0.8$

Real Power $=800 \mathrm{~kW}$

In terms of Watt hours, the real energy demand / consumption of the area is:

Real Energy Demand $/$ Consumption $=800 \mathrm{~kW} \times 12$ hours

Real Energy Demand / Consumption $=9.6 \mathrm{MWh}$

Data for the significant domestic consumption between 6:00pm and 6:00am were not available. Using this, a quite conservative estimate can be made as to the number of turbines that are needed for powering the area. Taking an Endurance E-3120 model into consideration which is rated for $50 \mathrm{~kW}$ at $10 \mathrm{~m} / \mathrm{s}(22 \mathrm{mph})$.

This wind speed is significantly higher than the mean value of $12.14 \mathrm{mph}$ at $10 \mathrm{~m}$ above the ground. The wind speeds can be scaled up to represent speeds at $80 \mathrm{~m}$ above the ground. Chadee and Clarke [14] estimate $80 \mathrm{~m}$ height wind speeds of $6.93 \mathrm{~m} / \mathrm{s}$ and $5.86 \mathrm{~m} / \mathrm{s}$ at Crown Point, Tobago and Piarco, Trinidad respectively. These values are still significantly lower than the $10 \mathrm{~m} / \mathrm{s}$ rating of the E-3120. The minimum number of turbines that would be required for power generation per day, assuming higher wind speeds and minimal 6:00 pm to 6:00 am consumption, both unrealistic expectations, would be:

Turbines $=800 / 50$

Turbines $=16$ units

This is a low number of turbines but valid only for ideal conditions.

\section{Costs}

To begin the cost of each, and every wind farm project will be different in many ways due to the environment in which they are deployed. The one factor that usually stays around the same pricing style in most projects is the costs associated with the acquisition of the turbines themselves. The varying measure of the costs can be associated with all the other aspects of the construction of the farm as well as the distribution method due to the varying geographical characteristics as well as the local additional cost differences among differing countries. Figure 3 shows multiple off-shore wind projects over a few years and how the percentages of the total price of each project is allocated [15].

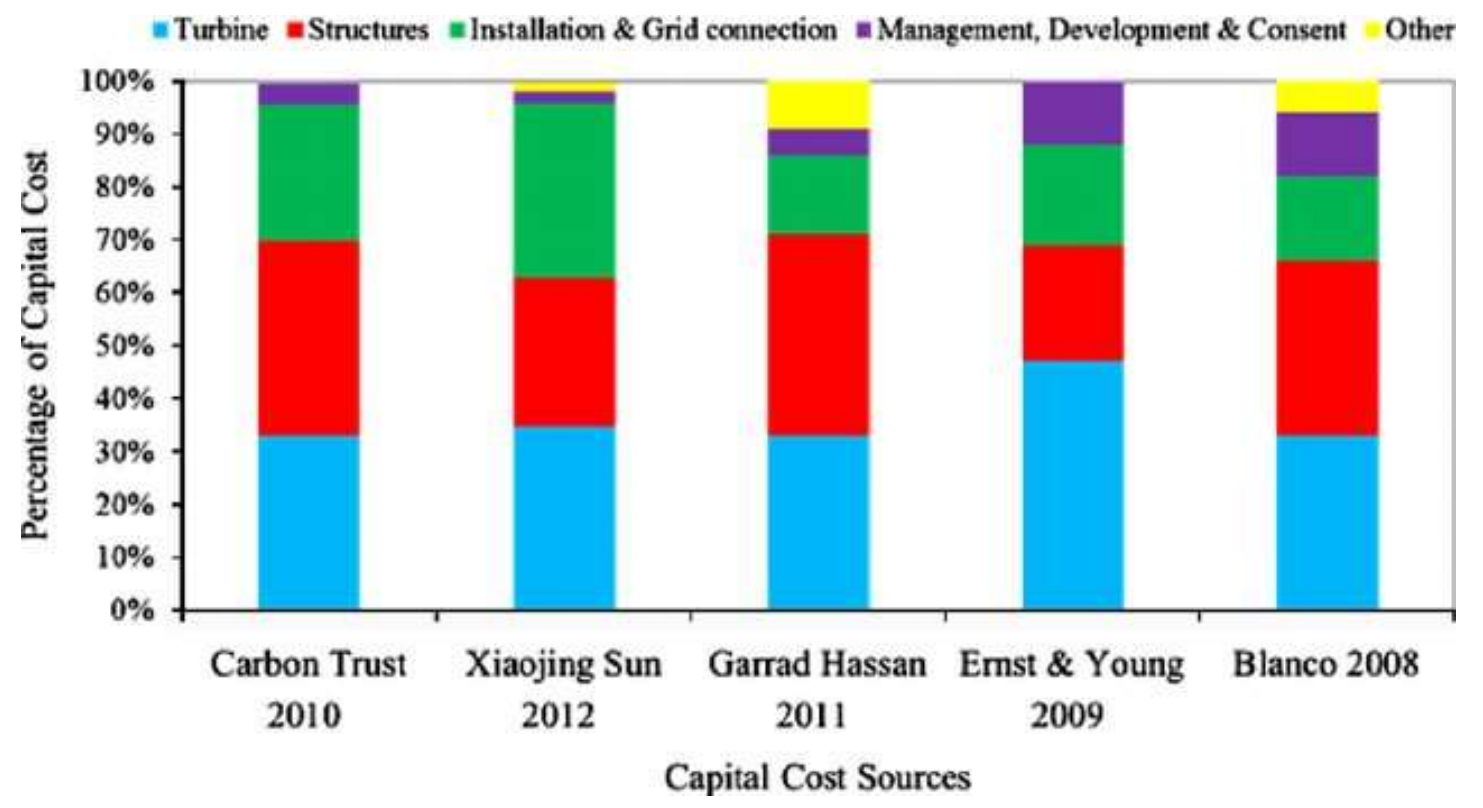

Figure 3: Image showing the cost percentages spread for various wind farm projects

Figure 3 shows that for a full-size wind farm, between $30 \%$ and $50 \%$ of the project cost came from the turbine alone. In terms of turbine pricing alone using the same turbine model and the amount needed as calculated 
above, the cost for obtaining the turbines required could be found. While the prices of wind turbines do vary, according to one online market place the asking price for an individual Endurance E-3120 model turbine can be shown to be US\$325,000. Scaling this value up to the amount required, which is 16 units, gives a total of US\$ 5,200,000.00 as just the initial cost of entry. There are other considerations to the installation of a wind farm beyond just the acquisition of the turbine itself. Using that above mentioned $30 \%$ to $50 \%$ cost approximation, the total costing with all other services included can be shown to be between US\$10.4 million and US\$ 17.3 million in total costs for the project which seems to be a bit high for a project to service a small area only.

\section{Discussion and Conclusions}

The goal behind this project was to discover if a venture into wind energy in the Manzanilla Community was a wise investment. The wind data discovered and displayed in this work shows that the potential for it to be used as a power source as compared to some other installations and countries, while slightly lower, is indeed technically possible. Even though the data acquired for this study was not from the exact location, it was from the same coastline, and was therefore quite representative of the area of interest in Manzanilla.

In comparison with a project done on the feasibility of offshore wind farms in the Bahamas, the wind speeds found in the Bahamas compared well to local wind speeds. In that study the average monthly wind speed was found to be $5.4 \mathrm{~m} / \mathrm{s}$ or $12.08 \mathrm{mph}$ which is comparable to wind speeds locally determined in this study. The present study concluded that these wind conditions were suitable for wind energy production.

While researching the area, it was discovered to be home to a variety of wildlife and plant life and as such, in order to maximize use of wind energy on land the eco system established would have to be disrupted both while on land and at sea. The goal of accessing renewable energy resources is to be able to power our everyday needs without harshly affecting the environment. In installing these structures, the risk of environmental harm in terms of animal injury is increased.

The costs of the turbines themselves are varied. There are quotable figures, but they are based upon used turbines and can vary from seller to seller.

In going forward, this research can be used as a starting point for further studies to be conducted. Due to the high costs of installation there could be partnerships between governmental powers and the private sector to introduce this type of system for an area larger than the area of study. This can allow the country to begin to diversify energy production away from natural gas and into renewable resources. It can also serve as a method of showing care to communities that deal with power fluctuations and interruptions.

\section{References}

[1] D. Gielen, F. Boshell, D. Saygin, M. Brazalian, N. Wagner, R. Gorini. 2019. The role of renewable energy in the global energy transformation. Energy Strategy Reviews 24 (2019) 38-50.

[2] Ministry of Energy and Energy Industries | Electric Power. (2018). Retrieved from http://www.energy.gov.tt/our-business/electric-power/

[3] Google. (2018). Map of a section of Manzanilla [Image]. Retrieved from https://www.google.tt/maps/@ 10.5208929,-61.0479268,2885m/data=!3m1!1e3

[4] Committee on Assessment of Research Needs for Wind Turbine Rotor Materials Technology, Energy Engineering Board, Commission on Engineering and Technical Systems, National Research Council, 1991. Assessment of research needs for wind turbine rotor materials technology. National Academy Press.

[5] K. Ramnarine-Ramsawak, N. Ramroop, (2018). Environmental Feasibility of Offshore Wind Farms for Trinidad [eBook] (p. 2). San Fernando: University of Trinidad and Tobago.

[6] X. Chadee, R. Clarke. 2013. Air Density Climate of Two Caribbean Tropical Islands and Relevance to Wind Power. ISRN Renewable Energy 2013 (2013). 
[7] Renewable Energy Businesses in Trinidad \& Tobago. (2016). Retrieved from http://energy.sourceguides.com/businesses/byGeo/byC/Trinidad\&Tobago/Trinidad\&Tobago.shtml [8] Framework for the development of a renewable energy policy for Trinidad and Tobago. (2011). Retrieved from http://www.energy.gov.tt/wp-content/uploads/2014/01/Framework-for-the-development-of-arenewable-energy-policy-for-TT-January-2011.pdf

[9] Appliance Usage - Trinidad and Tobago Electricity Commission. (2017). Retrieved from http://ttec.co.tt/default/appliance-usage

[10] Windfinder, Wind, waves and weather forecast; Trinidad / Mayaro Beach. Retrieved from https://www.windfinder.com/forecast/trinidad_mayaro_beach/birdseye

[11] WeatherSpark. Average Wind Speed [Image]. Retrieved from https://weatherspark.com/y/28635/Average-Weather-in-Rio-Claro-Trinidad-\&amp;-Tobago-Year-

Round\#Sections-Sources

[12] L. Daniels, 2007. Windustry. Chapter 8: Costs. Midwest Wind Energy Centre. Retrieved from http://www.windustry.org/community_wind_toolbox_8_costs

[13] How much does a wind turbine cost? - Renewables First. The Hydro and Wind Company. Retrieved from https://www.renewablesfirst.co.uk/windpower/windpower-learning-centre/how-much-does-a-farm-windturbine-small-wind-farm-turbine-cost/

[14] X. Chadee, R. Clarke. 2018. Wind resources and the levelized cost of wind generated electricity in the Caribbean islands of Trinidad and Tobago. Renewable and Sustainable Energy Reviews 81 (2018) 2526-2540. [15] P. Higgins, A. Foley. 2014. The evolution of offshore wind power in the United Kingdom. Renewable and Sustainable Energy Reviews 37(2014) 599-612. 